\title{
Human milk for neonatal pain relief during ophthalmoscopy*
}

\author{
O LEITE HUMANO NO ALÍVIO DA DOR NEONATAL NO EXAME DE FUNDO DE OLHO
}

\author{
LA LECHE HUMANA EN EL ALIVIO DEL DOLOR NEONATAL EN EL EXAMEN DE FONDO \\ DE OJO
}

\author{
Laiane Medeiros Ribeiro1, Thaíla Corrêa Castral' ${ }^{2}$, Liciane Langona Montanholi ${ }^{3}$, \\ Mariana Firmino Daré ${ }^{4}$, Aline Carolina de Araújo Silva ${ }^{5}$, Sonir Roberto Rauber Antonini ${ }^{6}$, \\ Carmen Gracinda Silvan Scochi ${ }^{7}$
}

\begin{abstract}
Ophthalmoscopy performed for the early diagnosis of retinopathy of prematurity (ROP) is painful for preterm infants, thus necessitating interventions for minimizing pain. The present study aimed to establish the effectiveness of human milk, compared with sucrose, for pain relief in premature infants subjected to ophthalmoscopy for the early diagnosis of ROP. This investigation was a pilot, quasi-experimental study conducted with 14 premature infants admitted to the neonatal intensive care unit (NICU) of a university hospital. Comparison between the groups did not yield a statistically significant difference relative to the crying time, salivary cortisol, or heart rate (HR). Human milk appears to be as effective as sucrose in relieving acute pain associated with ophthalmoscopy. The study's limitations included its small sample size and lack of randomization. Experimental investigations with greater sample power should be performed to reinforce the evidence found in the present study.
\end{abstract}

\section{DESCRIPTORS}

Pain

Infant, premature

Milk, human

Retinopathy of prematurity

Maternal-child nursing

\section{RESUMO}

O exame de fundo de olho para o diagnóstico precoce da retinopatia da prematuridade causa dor no prematuro, sendo necessárias intervenções que a minimizem. 0 objetivo foi investigar a efetividade do leite humano para alívio da dor em prematuros submetidos ao exame de fundo de olho para diagnóstico precoce da doença, em comparação com a sacarose. Tratou-se de um estudo piloto de caráter quase experimental, realizado com 14 prematuros internados na unidade neonatal de um hospital universitário. Na comparação entre os grupos, não houve diferença estatística significativa relacionada à duração do tempo de choro, concentração do cortisol salivar e frequência cardíaca. O leite humano parece ser tão efetivo quanto a sacarose no alívio da dor aguda relacionada ao exame. Tem-se como limitação o tamanhoreduzido da amostra e a falta de randomização. É necessária a realização de estudos experimentais com maior poder amostral para fortalecer as evidências encontradas.

\section{DESCRITORES \\ Dor \\ Prematuro \\ Leite humano \\ Retinopatia da prematuridade \\ Enfermagem materno-infantil}

\begin{abstract}
RESUMEN
El examen de fondo de ojo para el diagnóstico precoz de retinopatía prematura causa dolor en el prematuro, siendo necesarias intervenciones que la minimicen. El objetivo fue investigar la efectividad de la leche humana para el alivio del dolor en los prematuros sometidos al examen de fondo de ojo para el diagnóstico precoz de la enfermedad, en comparación con la sacarosa. Estudio piloto de carácter cuasi-experimental, realizado con 14 prematuros internados en la unidad neonatal de un hospital universitario. En la comparación entre los grupos, no hubo diferencia estadística significativa relacionada a la duración del tiempo del llanto, la concentración del cortisol salival y la frecuencia cardiaca. La leche humana parece ser tan efectiva como la sacarosa en el alivio del dolor agudo debido al examen. Una limitación fue el reducido tamaño de la muestra y la falta de aleatorización. Es necesaria la realización de estudios experimentales con mayor tamaño de muestra para fortalecer las evidencias encontradas.
\end{abstract}

\section{DESCRIPTORES \\ Dolor \\ Prematuro \\ Leche humana \\ Retinopatía de la prematuridad \\ Enfermería maternoinfantil}

\footnotetext{
* Extracted to the doctoral thesis "O leite humano e sacarose $25 \%$ no alívio da dor no prematuro submetido ao exame de fundo de olho: ensaio clínico randomizado", Ribeirão Preto School of Nursing, University of São Paulo,Brasil, 2012. ${ }^{1}$ PhD in Ribeirão Preto School of Nursing, University of São Paulo. Adjunct I Professor, University of Brasilia. Brasília, DF, Brasil lainha@gmail.com ${ }^{2}$ PhD in Ribeirão Preto School of Nursing, University of São Paulo. Adjunct I Professor, Federal University of Goiás. Goiânia, GO, Brasil. thaccastral@gmail.com ${ }^{3}$ PhD student, Graduate Program in Public Health Nursing, Ribeirão Preto School of Nursing, University of São Paulo. Scholarship granted by the São Paulo Research Foundation (FAPESP). Ribeirão Preto, SP, Brasil. licianelm@ gmail.com ${ }^{4} \mathrm{PhD}$ student, Graduate Program in Public Health Nursing, Ribeirão Preto School of Nursing, University of São Paulo .Scholarship granted by Coordination for the Improvement of the Higher Level Personel (CAPES). Ribeirão Preto, SP, Brasil. mari_dare@hotmail.com. ${ }^{5}$ Master student, Graduate Program in Public Health Nursing, Ribeirão Preto School of Nursing, University of São Paulo. Ribeirão Preto, SP, Brasil. aline_carol26@hotmail.com. ${ }^{6}$ PhD, Professor, Ribeirão Preto School of Medicine, University of São Paulo. Ribeirão Preto, SP, Brasil. antonini@fmrp.usp.br. ${ }^{6}$ Head Professor, Ribeirão Preto School of Nursing, University of São Paulo. CNPq B1 research grant (Research on Productivity). Ribeirão Preto, SP, Brasil. cscochi@eerp.usp.br
} 


\section{INTRODUCTION}

The diagnosis of retinopathy of prematurity (ROP) is performed via ophthalmoscopy. ROP involves abnormal development of the retinal blood vessels and occurs during the first days of life in premature infants ${ }^{(1)}$. In Latin America and the Caribbean, approximately 42,000 infants with birth weights less than 1,500 grams require screening for ROP every year, and 4,300 require treatment. When ROP is not treated, or if treatment is inadequate, $50 \%$ of the affected infants might become blind ${ }^{(1)}$.

Brazil ranks $72^{\text {nd }}$ relative to the international prevalence of ROP, which was estimated as $14.2 \%$ in $2004^{(2)}$. Ophthalmoscopy is one of the most commonly performed procedures in neonatal intensive care units (NICUs), and although painful, it is crucial to prevent visual impairments that might progress into blindness ${ }^{(3)}$.

Pain triggers compensatory mechanisms involving the autonomous nervous system, causing changes in the heart rate (HR), respiratory rate (RR), arterial pressure, and oxygen saturation $\left(\mathrm{SatO}_{2}\right)$, as well as peripheral vasoconstriction, sweating, pupil dilation, and increased release of catecholamines and adrenocorticosteroids ${ }^{(4-5)}$. In addition to the physiological changes, behavioral responses occur, such as crying, changes in facial expression, and altered sleep/ wake patterns $s^{(6)}$.

Among the methods investigated to reduce the pain associated with ophthalmoscopy in premature infants, a systematic review included the use of topical anesthetics, sucrose, developmental care, and the Newborn Individualized Care and Assessment Program - NIDCAP(7). Instillation of one or two drops of $5 \%$ proparacaine in the conjunctival sac was found to reduce the scores on the Premature Infant Pain Profile (PIPP) by 2.5 compared with saline solution; however, in another study, neither the physiological indicators (i.e., HR, RR, or systolic and diastolic indexes) nor crying exhibited significant differences compared with saline solution. Developmental care (non-nutritive sucking $+24 \%$ sucrose + facilitated tucking + holding the baby in the arms) and the NIDCAP did not shorten the time necessary for the vital signs to return to the baseline, nor did these methods reduce the PIPP scores compared with no treatment; however, the salivary cortisol before and after ophthalmoscopy was lower in the premature infants subjected to the NIDCAP $(p=0.017)$. Oral sucrose at a concentration of $24 \%$ to $33 \%$ in single $(0.12 \mathrm{ml}$ to $2 \mathrm{ml}$ ) or repeated doses (three 0.1-ml doses), either combined or not combined with non-nutritive suction, reduced the average PIPP score $(95 \%$ confidence interval $(\mathrm{Cl})=0.41 / 2.35)$ by 1.8 compared with distilled water, normal saline solution, and facilitated tucking or holding the baby $(p=0.005)$. The authors of the abovementioned systematic review concluded that the PIPP scores remained high during ophthalmoscopy (average score $=10.5$, with a score $\geq 6$ indicating the presence of pain) and emphasized the necessity to investigate other analgesic methods ${ }^{(7)}$.

Nonetheless, regarding sucrose, a study ${ }^{(8)}$ not included in the abovementioned review analyzed the analgesic effect of $0.2 \mathrm{ml}$ of $24 \%$ sucrose combined with the use of a pacifier and facilitated tucking. Treatment with sucrose was associated with lower scores on the Neonatal Pain Agitation and Sedation Scale (N-PASS) during ophthalmoscopy soon after speculum insertion ( 6.5 vs. $5 ; p=0.02)$ and during scleral manipulation (9.5 vs. $7.5 ; p=0.03$ ) compared with placebo (distilled water administered orally). In addition, the premature infants who were given sucrose exhibited a lower percentage of side effects, such decreased SatO2 and bradycardia (1 vs. $4 ; \mathrm{p}=0.18)^{(8)}$.

Because of the inconsistent results yielded by the abovementioned methods to reduce pain during ophthalmoscopy in premature infants, other types of interventions should be investigated. In addition, the long-term effects of the repeated use of sucrose on the children's development are not known ${ }^{(9)}$.

Human milk is proven to have analgesic properties in procedures such as heel and vein punctures $^{(10)}$; however, human milk has not yet been tested for ophthalmoscopy. Thus, we questioned whether human milk might also be effective in reducing the acute pain associated with ophthalmoscopy in premature infants.

A further motive behind the present study is the fact that human milk is natural and affords countless benefits to premature infants ${ }^{(10)}$. Its use is further justified within the context of the strategies to stimulate breastfeeding, which are aimed at better motherand-child care ${ }^{(11)}$.

We chose sucrose instead of a placebo (distilled water) as the control because the use of sucrose is currently recommended as a method to minimize acute pain ${ }^{(12-13)}$. In addition, children have the right not to experience pain, as established by the Children and Adolescent's Rights in the Hospital (Direitos da Criança e do Adolescente Hospitalizados) $)^{(14)}$ and the Universal Declaration of Premature Babies' Rights (Declaração Universal dos Direitos do Bebê Prematuro) ${ }^{(15)}$. Consequently, based on the current recommendations for acute neonatal pain relief, the proper pain treatment was granted to all the premature infants who participated in the present study.

The aim of the present study was to compare the effectiveness of human milk vs. $25 \%$ sucrose in premature infants subjected to ophthalmoscopy for the early diagnosis of ROP. The underlying hypothesis was that human milk is as effective as sucrose for relieving acute pain in premature infants subjected to ROP ophthalmoscopy.
Human milk for neonatal pain relief during ophthalmoscopy Ribeiro LM, Castral TC, Montanholi LL, Daré MF Silva ACA, Antonini SRR, Scochi CGS 


\section{METHOD}

The present investigation was a pilot study with a quasi-experimental design as it involved one independent variable (human milk) but did not comply with the randomization criteria typical of true experiments ${ }^{(16)}$.

In the present study, the intervention group (IG) was given human milk from a milk bank because many premature infants are immature and have difficulty sucking efficiently at their mothers' breast, and the mothers often exhibit deficient milk secretion. The control group (CG) was orally administered $25 \%$ sucrose $(0.5 \mathrm{ml} / \mathrm{Kg}) 2$ minutes before ophthalmoscopy according to the institutional protocol for acute neonatal pain relief. Immediately before the eye exam, the ophthalmologist instilled one drop of the anesthetic collyrium (proxymetacaine) in each eye of all the participants. In addition, all the participants underwent facilitated tucking during the eye exam.

The study was conducted in the NICU of the Clinical Hospital, Ribeirão Preto School of Medicine - University of São Paulo (Hospital das Clínicas da Faculdade de Medicina de Ribeirão Preto-USP/HCFMRP-USP), which is a tertiary reference center for perinatal care, from November 2010 to May 2011. The study was approved by the hospital's research ethics committee (process no. 1127/2010). The participants' anonymity was ensured, and the infants' mothers and/or guardians (in the case of adolescent mothers) signed an informed consent form.

The convenience sample included 14 premature infants, who were given sucrose $(n=9)$ or human milk $(n=5)$, provided they met the following inclusion criteria: gestational age (GA) $\leq 32$ weeks and 6 days, birth weight $\leq 1,500$ grams, first ophthalmoscopy scheduled for the fourth to sixth week of life, clinical stability with the physiological parameters within the normal range before the test, and at least one hour since the last feeding. Premature infants under assisted ventilation; with grade III or IV intraventricular hemorrhage or subsequent leukomalacia; with congenital diseases affecting the nervous system; with neurological or kidney malformations or impairment; or using opiates, corticosteroids, or other drugs that interfere with the nociceptive response were excluded.

Human milk or sucrose was administered orally 2 minutes before ophthalmoscopy using a 3-ml needle-free syringe. The CG was given $0.5 \mathrm{ml} / \mathrm{kg}$ of $25 \%$ sucrose, according to the institutional protocol, and the IG was given $2 \mathrm{ml}$ of human milk from a milk bank.

The response of the premature infants to the painful procedure was assessed according to the following variables: crying time, $\mathrm{HR}$, and salivary cortisol concentration. The facial expression was not included in the analysis because the ophthalmoscopic procedure precludes the proper visualization of the face and thus makes the coding of facial gestures on images impossible. The following data were collected from the participants' clinical records: GA, birth weight, corrected age, postnatal age, and Apgar score.

The crying time and HR were measured at three time points: baseline - B ( 5 minutes before the procedure), during ophthalmoscopy $-\mathrm{P}$ (procedure, which lasted 3 to 12 minutes), and recovery - $\mathrm{R}$ (5 minutes after the procedure). HR was measured via two cardiac electrodes placed on the chest of the newborn and connected to a Polar RS300X monitor; the corresponding data were later transferred to the Polar Training Software. Crying was identified by analyzing the images of the infants' faces recorded with a camera (Sony - Digital Handcan, model DVD92) at the three established time points.

To measure the salivary cortisol, saliva was collected before (baseline cortisol) and at 30 minutes and $60 \mathrm{mi}-$ nutes after the procedure (response and recovery cortisol, respectively) using a needle-free $21 \mathrm{G}$ scalp vein set connected to a 3-ml syringe, which provided the necessary negative pressure to collect $0.5 \mathrm{ml}$ to $1 \mathrm{ml}$ of saliva. The samples were centrifuged and measured twice by a technician at the Laboratory of Endocrinology and Metabolism of the hospital's Department of Internal Medicine. For this purpose, the radioimmunoassay method was used, and the intra- and interassay coefficients were $3.7 \%$ and $12.5 \%$, respectively.

The database was first generated on an EXCEL spreadsheet to encode the variables; the data were entered twice to ensure their reliability. After the comparison of these two databases and the correction of divergences, the data were exported to the Statistical Package for the Social Sciences-SPSS (version 19.0) software.

Descriptive statistics (mean and standard deviation) was used for the quantitative variables, and the distribution of frequencies was used for the qualitative (or categorical) variables. The normality of the distribution of the average results of the quantitative variables (GA, birth weight, corrected age, postnatal age, Apgar score, duration of ophthalmoscopy, HR, salivary cortisol, and crying time) was assessed by the Kolmogorov-Smirnov test. The intergroup comparison of the distribution of the variable gender was performed using Fisher's exact test. The intergroup comparison of the average values of the variables $\mathrm{GA}$, birth weight, corrected age, postnatal age, Apgar score, and exam duration was performed using Student's t-test. The intergroup comparison of the average values of $\mathrm{HR}$, crying time, and salivary cortisol corresponding to the three different time points was performed using the repeated-measures analysis of variance (RM-ANOVA). The within-subjects factor used in each ANOVA corresponded to the three time points of data collection. In the case of RM-ANOVA, the sphericity assumption of the variance matrix was investigated, which is essential in this type of analysis. The significance level was established as $5 \%$. 


\section{RESULTS}

Table 1 lists the means and standard deviations of the variables corresponding to the participants' birth per group, together with the corresponding $p$ values. The results of Student's t-test revealed that the birth weight, Apgar score, GA, corrected age, and postnatal age did not exhibit significant differences between the groups. Of the 14 premature infants included in the study, eight were female and six were male; their distribution in the groups was similar ( $p=0.091)$.

Table 1 - Description of the neonatal characteristics - Ribeirão Preto, SP, Brazil, 2012

\begin{tabular}{lccccc}
\hline \multirow{2}{*}{ Variables } & \multicolumn{2}{c}{ GI } & \multicolumn{3}{c}{ GC } \\
\cline { 2 - 6 } & $\boldsymbol{\chi}-$ & Sd & $\boldsymbol{\chi}-$ & Sd & $\mathbf{p}^{*}$ \\
\hline Birth weight (g) & 1194,00 & $\pm 114,204$ & 1233,33 & $\pm 323,574$ & 0,800 \\
Apgar (1 minute) & 6,00 & $\pm 2,00$ & 7,11 & $\pm 1,97$ & 0,333 \\
Apgar (5 minutes) & 8,4 & $\pm 1,34$ & 8,89 & $\pm 1,17$ & 0,489 \\
Gestational age (days) & 218,4 & $\pm 1,14$ & 222,33 & $\pm 21,63$ & 0,697 \\
Corrected age (days) & 257,6 & $\pm 10,36$ & 260,89 & $\pm 11,96$ & 0,944 \\
Postnatal age (days) & 39,2 & $\pm 10,62$ & 38,56 & $\pm 18,26$ & 0,616 \\
\hline
\end{tabular}

$\mathrm{IG}=$ intervention group, $\mathrm{CG}=$ control group $\chi-=$ mean $\mathrm{Sd}=$ standard deviation *Student's t-test $\alpha=0.05$

The ophthalmoscopy lasted 3 to 12 minutes and was longer in the IG compared with the CG $(8.9 \pm 3.2$ minutes vs. $4.3 \pm 1.5$ minutes, $p=0.029)$.

Figure 1 depicts the average HR at each investigated time point.

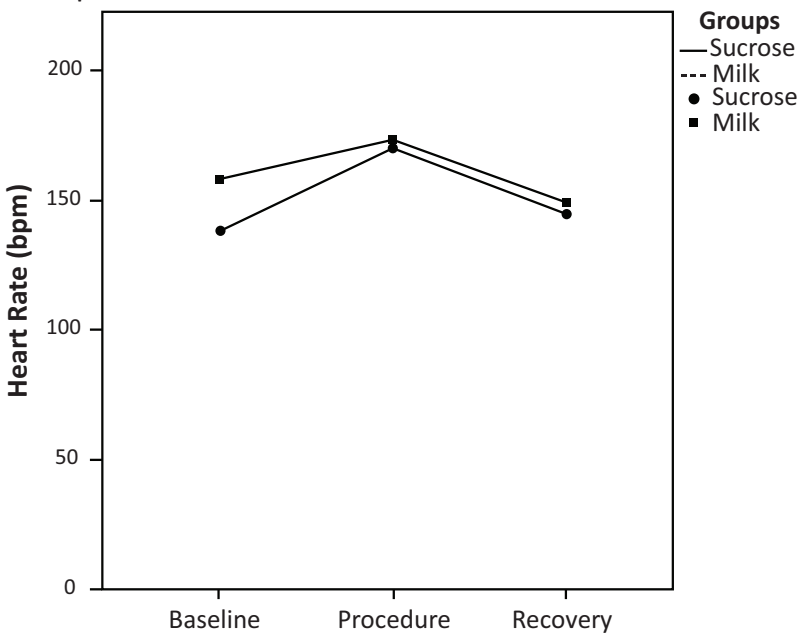

Figure 1 - VAverage HR values at each investigated ophthalmoscopic time point, per group - Ribeirão Preto, SP, Brazil, 2012.

Comparison of the average HR among the three investigated time points by RM-ANOVA revealed a statistically significant difference $[F(2,24)=17.529 ; p<0.005]$. These results demonstrated that the participants' average HR exhibited changes along the three investigated time points, being higher during the procedure compared with during the baseline and recovery; however, the average HR did not exhibit significant differences between the IG and the CG $[F(2,24)=1.876 ; p=0.175]$. These findings indicate that, independent of the treatment provided, the HR did not vary between the groups at any investigated time point.
Table 2 - Mean and standard deviation of the crying time at each investigated time point per group - Ribeirão Preto, SP, Brazil, 2012

\begin{tabular}{lccc}
\hline Time points & Group & n & $\begin{array}{c}\text { Crying time } \\
\chi-(D P)\end{array}$ \\
\hline FB & Sucrose & 9 & $17,33(46,1)$ \\
& Milk & 4 & $14,25(28,5)$ \\
FP & Sucrose & 9 & $93,22(76,6)$ \\
& Milk & 4 & $270(188,1)$ \\
FR & Sucrose & 9 & $6,78(18,8)$ \\
& Milk & 4 & $5,00(4,9)$ \\
\hline
\end{tabular}

$\mathrm{n}=$ sample size; $\boldsymbol{\chi}-=$ mean; $\mathrm{SD}=$ standard deviation

Comparison of the average crying time percentage among the investigated time points (via RM-ANOVA) revealed the effect of the factor time, i.e., the crying time exhibited significant differences along the investigated time points [Wilks' Lambda $=0.295 ; \mathrm{F}(2,10)=11.992$; $\mathrm{p}<0.005]$. Thus, the average crying time percentage was greater at $P$ compared with at $B(p<0.001)$ and $R$ $(p<0.001)$. However, the crying time did not exhibit significant differences between the IG and the CG [Wilks' Lambda=0.60; $F(2,10)=3.33 ; p=0.078]$. The crying time did not exhibit a statistically significant difference $(p=0.069)$ between the groups.

Figure 2 depicts the average salivary cortisol at the three investigated time points $(B, P$, and $R)$.

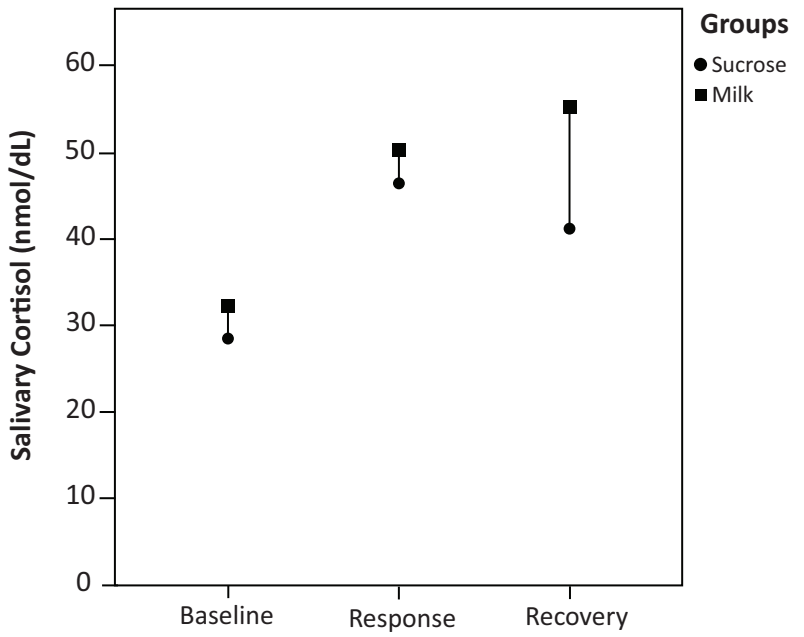

Figure 2 - Average salivary cortisol (nmol/dl) at the three investigated ophthalmoscopic time points relative to ophthalmoscopy per group - Ribeirão Preto, SP, Brazil, 2012.

Comparison of the average salivary cortisol among the three investigated time points (via RM-ANOVA) revealed significant differences [Wilks' Lambda $=0.482$; $F(2,11)=5.903 ; p=0.018]$. The average salivary cortisol response was higher than at the baseline $(p=0.007)$; however, there was no significant difference between the response and recovery salivary cortisol $(p=0.982)$. The average salivary cortisol did not exhibit a significant difference between the IG and the CG [Wilks' Lambda=0.739; $F(2,11)=1.947 ; p=0.189]$. 


\section{DISCUSSION}

The main finding of the present study concerns the analgesic effect of human milk, which did not differ from the effect of sucrose during ophthalmoscopy. Indeed, human milk appears to have been as effective as sucrose for inducing pain relief in the investigated sample. Notably, the present investigation is the first to compare the effectiveness of human milk to sucrose during ophthalmoscopy.

In a systematic review ${ }^{(10)}$, maternal milk ( 2 to $5 \mathrm{ml}$ ), either combined or not combined with non-nutritive sucking, was compared with distilled water, no treatment, sucrose, glucose, pacifier use, and tucking during heel and vein punctures in premature and full-term infants. The use of maternal milk was associated with lower increases of HR and pain scores (Neonatal Facial Coding System - NFCS) compared with the control group; however, the crying time and the $\mathrm{SatO}_{2}$ did not exhibit statistically significant differences. The authors concluded that maternal milk might be used for pain relief in newborn infants, with effects similar to those of sucrose and glucose.

A more recent study compared the effectiveness of 2 $\mathrm{ml}$ of pumped maternal milk (IG) compared with $2 \mathrm{ml}$ of $25 \%$ glucose (CG) for pain relief during heel punctures in 42 borderline premature infants. Both solutions were administered 2 minutes before the heel puncture was performed to assess the capillary blood glucose. The PIPP scores were lower in the CG during the first 3 minutes after the end of the procedure (CG: $25.6 \%$ vs. IG: $60.0 \%$; $p=0.002$ ), although these scores exhibited a significant reduction in both groups over time $(F=15.62, p=0.001)$. Compared with the IG, the CG participants exhibited a lower incidence of crying (CG: $42.2 \%$ vs. IG: $78.6 \%$; $p=0.001$ ) and a shorter crying time after the heel puncture (CG: $14.53 \%$ vs. IG: $32.02 \% ; p=0.014$ ). The authors concluded that single doses and small volumes of milk are not effective for neonatal pain relief but that greater volumes might yield better results ${ }^{(11)}$. In contrast to that study, we did not use the participants' mothers' milk, in addition to using a different pain stimulus, which might have contributed to the divergence in the results.

Another investigation compared the effect of one dose $(2 \mathrm{ml})$ vs. two doses of pumped maternal milk, one dose $(2 \mathrm{ml})$ vs. two doses of $12.5 \%$ sucrose, and one dose (1 $\mathrm{ml}$ ) vs. two doses of distilled water in 142 full-term infants subjected to heel punctures. In the groups that were given repeated doses, $2 \mathrm{ml}$ of the corresponding substance were administered both 2 minutes prior to and immediately before the procedure. The group that was given a single dose of sucrose exhibited the shortest crying time (82 seconds); however, this variable did not exhibit significant differences among the groups $(p=0.053)$. Similarly, the NFCS scores did not demonstrate statistically significant differences among the groups $(p=0.068)$. The authors concluded that two doses of sucrose or pumped maternal milk were not more effective than a single dose for relieving the pain associated with heel punctures ${ }^{(17)}$.
The divergence among the findings relative to the effect of maternal milk on neonatal pain relief is evident. Therefore, it is necessary to conduct studies comparing the effectiveness of human milk vs. pumped maternal milk, as well as the effectiveness of different volumes of human milk, for providing pain relief in premature infants.

The present study also revealed that the pain indicators (HR, crying time, and salivary cortisol) increased in both the premature infants who were given human mi$\mathrm{lk}$ and the infants who were given sucrose during ROP ophthalmoscopy.

Moreover, other investigators have found changes in the physiological and behavioral indicators that are characteristic of the global response to stress following an acute painful stimulus, which include (but are not limited to) autonomous, metabolic, and behavioral changes ${ }^{(18-19)}$. Due to the specific nature and duration of ophthalmoscopy, it does not seem probable that a single intervention might suffice to reduce the associated pain ${ }^{(7)}$. Therefore, further clinical trials are necessary to compare the combined effect of human milk and other interventions, such as the kangaroo position and non-nutritive sucking.

In the present investigation, we sought to assess the changes in the salivary cortisol of premature infants subjected to ophthalmoscopy because pain may activate the hypothalamic-pituitary-adrenal (HPA) axis, inducing an endocrine response in premature infants that manifests as increased cortisol levels ${ }^{(18)}$. Cortisol affects the metabolism, cardiovascular system, and central nervous system ${ }^{(19)}$. Salivary cortisol has been used in studies to assess the effects of non-pharmacological interventions against pain in newborn infants, including sucrose, the kangaroo position, and developmental care $\mathrm{c}^{(20-22)}$.

Only one previous study has assessed salivary cortisol in premature infants subjected to ophthalmoscopy. In that study, one group was administered NIDCAP strategies, and the other group was provided the standard care only. The salivary cortisol was lower 60 minutes after the end of the procedure (compared with $30 \mathrm{mi}$ nutes after) in both groups; however, 4 hours later, the salivary cortisol was reduced in the NIDCAP group only, which indicates a greater effect of treatment on the premature infants' recovery ${ }^{(22)}$. By contrast, in the present study, the salivary cortisol did not differ 30 and 60 minutes after the end of the procedure in either group (i.e., treated with sucrose vs. human milk). Thus, we recommend that future studies investigate the long-term effect of human milk by measuring the salivary cortisol 2 to 4 hours after ophthalmoscopy.

Certain limitations of the present study should be mentioned, such as the small sample size and the lack of randomization, which do not allow for extrapolating the results or establishing causal relationships. In addition, the differences in the ophthalmoscopic durations might have interfered with the results. This difference might 
have been partially due to the large number of professionals who assessed the infants, as the study was performed at a teaching hospital.

\section{CONCLUSIONS}

Human milk did not differ from sucrose in the pain relief afforded to premature infants during ophthalmoscopy. However, further clinical trials with the appropriate sample power are required before human milk can be recommended for the pain associated with ophthalmoscopy performed for ROP screening as a more widely accessible and natural approach compared with sucrose, in addition to including the mothers in the care provided.

O estudo apresenta resultados inéditos para a enfermaThe results of the present study are innovative in the nursing field related to managing ophthalmoscopy-associated

\section{REFERENCES}

1. Zin A, Florêncio T, Fortes Filho JB,Nakanami CR, Gianini N, Graziano RM,et al. Proposta de diretrizes brasileiras do exame e tratamento de retinopatia da prematuridade (ROP).ArqBras Oftalmol. 2007;70(5):875-83.

2. Gilbert C, Fielder A, Gordillo L,Quinn G, Semiglia R, Visintin P, et al. Characteristics of infants with severe retinopathy of prematurity in countries with low, moderate, and high levels of development: implications for screening programs. Pediatrics. 2005;115(5):e518-25.

3. Anand KJS, International Evidence-Based Group for Neonatal Pain. Consensus statement for the prevention and management of pain in the newborn. Arch PediatrAdolesc Med.2001;155(2):173-80.

4. Lawrence J, Alcock D, McGrath P, Kay J, MacMurray SB, Dulberg $C$. The development of a tool to assess neonatal pain. Neonatal Netw. 1993;12(6):59-66.

5. Sweet S, McGrath PJ. Physiological measures of pain. In: Finley GA, McGrath PJ, editors. Measurement of pain in infants and children, progress in pain research and management. Seattle: IASP Press, 1998. p. 59-82.

6. Guinsburg R, Balda Rde C, Berenguel RC, de Almeida MF, Tonelloto J, dos Santos AM, et al.Behavioral pain scales assessment in neonates. JPediatr (Rio J.). 1997;73(6):411-8.

7. Sun X, Lemyre B, Barrowman N, O'Connor M. Pain management during eye examinations for retinopathy of prematurity in preterm infants: a systematic review. ActaPaediatr. 2010;99(3):329-34.

8. O'Sullivan A, O'Connor M, Brosnahan D, McCreery K., Dempsey EM. Sweeten, soother and swaddle for retinopathy of prematurity screening: a randomised placebo controlled trial. Arch Dis Child Fetal Neonatal Ed. 2010;95(6):F419-22. pain in premature infants. Thus, our investigation contributes to increasing the quality of care provided to these infants and their relatives because, to improve their survival, this patient population must be extensively exposed to painful procedures. Another contribution of the present study is the possibility of broadening the scope of non-pharmacological interventions relative to ophthalmoscopy and the likelihood of including mothers as active participants in the care of their infants.

Finally, our investigation facilitated further reflection on the nursing care provided to premature infants subjected to ophthalmoscopy. Indeed, the tasks of nurses should also include orienting parents or guardians via educational strategies that increase their knowledge and enable them to have an active role in care as well as establishing comfort measures, such as NICU light and noise reduction, flexed positioning, and non-nutritive sucking.

9. Mitchell A, Stevens B, Mungan N,Johnson W, Lobert S, Boss B. Analgesic effects of oral sucrose and pacifier during eye examinations for retinopathy of prematurity. Pain ManagNurs. 2004;5(4):160-8.

10. Shah PS, Aliwalas LI, Shah V. Breastfeeding or breast milk for procedural pain in neonates. Cochrane Database Syst Rev. 2006;(3):CD004950.

11. Bueno M, Stevens B, Camargo PP, Toma E, Krebs VL, Kimura AF. Breast milk and glucose for pain relief in preterm infants: a noninferiority randomized controlled trial. Pediatrics. 2012;129(4):664-70.

12. Holsti L, Grunau RE. Considerations for using sucrose to reduce procedural pain in preterm infants. Pediatrics. 2010;125(5):1042-7.

13. Stevens B, Yamada J, Ohlsson A. Sucrose for analgesia in newborn infants undergoing painful procedures. Cochrane Database Syst Rev. 2010;(1):CD001069.

14. Brasil. Conselho Nacional de Defesa dos Direitos da Criança e do Adolescente. Resolução n. 41, de 13 de outubro de 1995. Dispõe sobre os Direitos da Criança e do Adolescente Hospitalizados. Diário Oficial da União, Brasília, 17 out. 1995. Seção I, p. 163-9.

15. Tavares L. Uma declaração universal de direitos para o bebê prematuro. Rio de Janeiro: Diagraphic; 2009.

16. Ribeiro PJ, Sabatés AL, Ribeiro CA. Utilização do brinquedo terapêutico, como um instrumento de intervenção de enfermagem, no preparo de crianças submetidas à coleta de sangue. Rev Esc Enferm USP.2001;35(4):420-8.

17. Ozdogan T, Akman I, Cebeci D, Bilgen H, Ozek E. Comparison of two doses of breast milk and sucrose during neonatal heel prick. Pediatr Int. 2010;52(2):175-9. 
18. Grabska J, Walden P, Lerer T, Kelly C, Hussain N, Donovan $\mathrm{T}$, et al. Can oral sucrose reduce the pain and distress associated with screening for retinopathy for prematurity? J Perinatol. 2005;25(1):33-5.

19. Dedovic K, Duchesne A, Andrews J, Engert V, Pruessner JC. The brain and the stress axis: the neural correlates of cortisol regulation in response to stress. Neuroimage. 2009;47(3):864-71.

20. Cignacco E, Denhaerynck K, Nelle M, Bührer C, Engberg S. Variability in pain response to a non-pharmacological intervention across repeated routine pain exposure in preterm infants: A feasibility study. ActaPaediatr. 2009;98(5):842-6.
21. Cong X, Ludington-Hoe SM, Walsh S. Randomized crossover trial of kangaroo care to reduce biobehavioral pain respondes in preterm infants: a pilot study. Biol Res Nurs. 2011;13(2):204-16.

22. KlebergA, Warren I, Norman E, MöreliusE, Berg AC, Mat-AliE, et al.Lower stress responses after Newborn Individualized Developmental Care and Assessment Program care during eye screening examinations for retinopathy of prematurity: a randomized study. Pediatrics. 2008;121(5):1267-78.

\section{Acknowledgements}

This study was funded by the National Council for Scientific and Technological Development (Conselho Nacional de Desenvolvimento Científico e Tecnológico - CNPq) no 303519/2010-0 (Research grant). 